\title{
ESTIMATION OF SHEAR WAVE VELOCITY FROM WIRELINE LOGS DATA FOR AMARA OILFIELD, MISHRIF FORMATION, SOUTHERN IRAQ
}

\author{
${ }^{1}$ Rwaida K. Abdul Majeed" and ${ }^{2}$ Ayad A. Alhaleem \\ ${ }^{1 \& 2}$ Petroleum Engineering Department, College of Engineering, University of Baghdad \\ *E-mail:rwaida@gmail.com
}

Received: 8 August 2019; accepted: 15 September 2019

\begin{abstract}
Shear wave velocity is an important feature in the seismic exploration that could be utilized in reservoir development strategy and characterization. Its vital applications in petrophysics, seismic, and geomechanics to predict rock elastic and inelastic properties are essential elements of good stability and fracturing orientation, identification of matrix mineral and gas-bearing formations. However, the shear wave velocity that is usually obtained from core analysis which is an expensive and time-consuming process and dipole sonic imager tool is not commonly available in all wells. In this study, a statistical method is presented to predict shear wave velocity from wireline log data. The model concentrated to predict shear wave velocity from petrophysical parameters and any pair of compressional wave velocity, porosity and density in carbonate rocks. The established method can estimate shear wave velocity in carbonate rocks with a correlation coefficient of close to unity.

Keywords: Petrophysics; shear wave velocity; Multiple regressions; Acoustic properties; Compressional velocity

\section{INTRODUCTION}

In many oil fields, only conventional borehole compensated sonic tool logs (BHC logs) or seismic velocity check shots are available to provide interval transit time $(\Delta t)$, the reciprocal of compressional wave velocity $(\mathrm{Vp})$. For a practical purpose such as in seismic modeling, amplitude variation with offset (AVO) analysis, and engineering applications, shear wave velocities or moduli were needed. In these applications, it is important to extract, either empirically or theoretically, the needed shear wave velocities or moduli from available compressional velocities or moduli (Wang, 2000). The shear wave velocity (Vs) has a large number of applications in petrophysical, seismic, and geomechanically studies (Kumar, 1976, Omnes, 1978, and Greenberg \& Castagna, 1992). Shear wave velocity is an important
\end{abstract}


parameter for the determination of several elastic rock properties, such as Young's modulus, Poisson's ratio, the rock compressibility factor, and Biot's coefficient (Widarsono et.al. 2001). These properties are commonly used to predict wellbore stability, select mud density, determine the critical production rate that minimized sand production, optimize casing design, analyze subsidence, and forecast the height, width, length, and direction of hydraulic fractures (Economides and Nolte, 2000). Also, Vs is applied in seismic technology used for reservoir characterization (Castagna et al., 1985).

The basic methods for determining the shear wave values in a reservoir should have the following data: well logs, laboratory measurements, and theoretical or statistical approaches.

During the past years, many studies have been done on elastic wave velocities (shear wave velocity) which focused on related petrophysical properties of rocks. Unfortunately, nearly all of these studies are about sandstone formations.

Regression analysis is one of the most predictive methods that has traditionally been used to correlate rock mechanical properties with other parameters (Dehghan et al. 2010).

Several researchers established empirical correlations to estimate the shear wave velocities (Pickett, 1963; Carroll, 1969; Han et al., 1986; Castagna et al., 1993; Eskandari et al., 2004; Brocher, 2005; Al-Kattan, 2008; Ameen et al., 2009, Al-Kattan, 2015). Empirical predictions are highly dependent upon the amount of data collected. Such predictions may also be used for well planning. Table (1) presents a number of relationships that have been reported for predicting shear waves from compressional waves. Thus, the prediction of Vs using compressional wave velocity is more reliable, especially in carbonates rocks.

Table 1: Previous empirical relationships for shear wave prediction

\begin{tabular}{|l|l|c|}
\hline Reference & Relationship of $\mathrm{Vs}(\mathrm{km} / \mathrm{sec})$ & Eq. No. \\
\hline (Pickett, 1963) & $V_{p} / V_{s}=1.9$ or $V_{s}=0.526 V_{p}$ for limestone & 1 \\
& $V_{p} / V_{s}=1.8$ or $V_{s}=0.556 V_{p}$ for dolomite & 2 \\
\hline (Carroll, 1969) & $V s=0.756090 V p^{0.81846}$ & 3 \\
\hline (Castagna et al., 1985\&1993) & $V_{s}=-0.05509 V_{p}^{2}+1.0168 V_{p}-1.0305$ & 4 \\
\hline (Freund, 1992) & $V_{s}=0.763 V_{p}-0.603$ & 5 \\
\hline (Eskandari et al., 2004) & $V s=-0.1236 \mathrm{Vp}^{2}+1.6126 \mathrm{Vp}-2.3057$ & 6 \\
\hline (Brocher, 2005) & $V_{s}=0.7858-1.2344 V_{p}+0.7949 V_{p}^{2}-0.1238 V_{p}^{3}+0.006 V_{p}^{4}$ & 7 \\
\hline (Ameen et al., 2009) & $V s=0.52 * V p+0.25251$ & 8 \\
\hline (Al-Kattan, 2015) & $V s=0.699 V p^{0.969}$ & 9 \\
\hline
\end{tabular}

However, most previous relationships have been developed from limited core measurements and there are very few attempts to predict the Vs of a field case. Many of the 
developed relationships consider the determination coefficient as a sufficient criterion to evaluate the accuracy of the empirical model, which may not always capture the total variation of rock independent variables. On the other hand, many studies presented recently have proved and shown the capability of using artificial intelligence modeling and fuzzy logic over empirical and statistical models for predicting the shear wave velocity from $\mathrm{P}$ wave velocity and other well $\log$ data such as neutron porosity and bulk density as inputs (Zoveidavianpoor, 2017; Tariq et.al., 2016; Bagheripour et.al, 2015; Nourafkan and Ilkhchi, 2015; Maleki et al. 2014; Tabari et.al.,2011; Rajabi et.al., 2010; Rezaee et.al, 2007).

This study presents a regression analysis (statistical method) was used to create a correlation to predict shear waves and among effective petrophysical properties in carbonate reservoirs using SPSS software. The development of empirical models in which the measurable well logs can provide an estimation of Vs will also be outlined.

\section{DATA ANALYSIS AND METHODOLOGY}

Data analysis was used to ensure that the relationship between input data and the outcomes is logical. Sonic wave data can be determined using logs or core plugs, yet logs provide large amounts of data and are a greater representation of a reservoir (Zoveidavianpoor et al. 2013). In this study, the regression analysis was employed to predict shear wave velocities from well logs of a productive carbonate (limestone) section of South-East Iraq (Amara field, Mishrif Formation). Figure (1) shows the variation histograms with a statistical evaluation of the log dataset, which contains 394 data values for Vp, Vs, porosity, Resistivity and gamma ray, and 394 data points for bulk density. In general, the frequency histograms of Vp, Vs NPHI, and RHOB appeared to be nearly symmetrical (Fig.1a, 1b, 1c, and 1e). Whereas, these of GR and Rt (Fig.1d and 1f) appeared to be skewed to the left.

In general, the petrophysical properties of the data set used in our analysis cover a wide range of exploration interest (table 2). While the range of $\mathrm{Vp}$ between 3.39 and $5.86 \mathrm{~km} / \mathrm{sec}$, Vs has a range between 1.81 and $3.10 \mathrm{Km} / \mathrm{sec}$, bulk density is between 2.18 and $2.72 \mathrm{gm} / \mathrm{cc}$, gamma-ray ranges from 0 and 150 API units, neutron porosity ranges from $1 \%$ and $33 \%$ and the Resistivity range from 0.35 and 32 Ohm.m. 


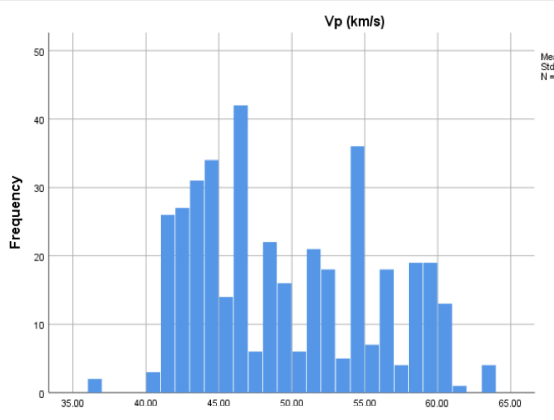

(a) $\mathbf{V p}$
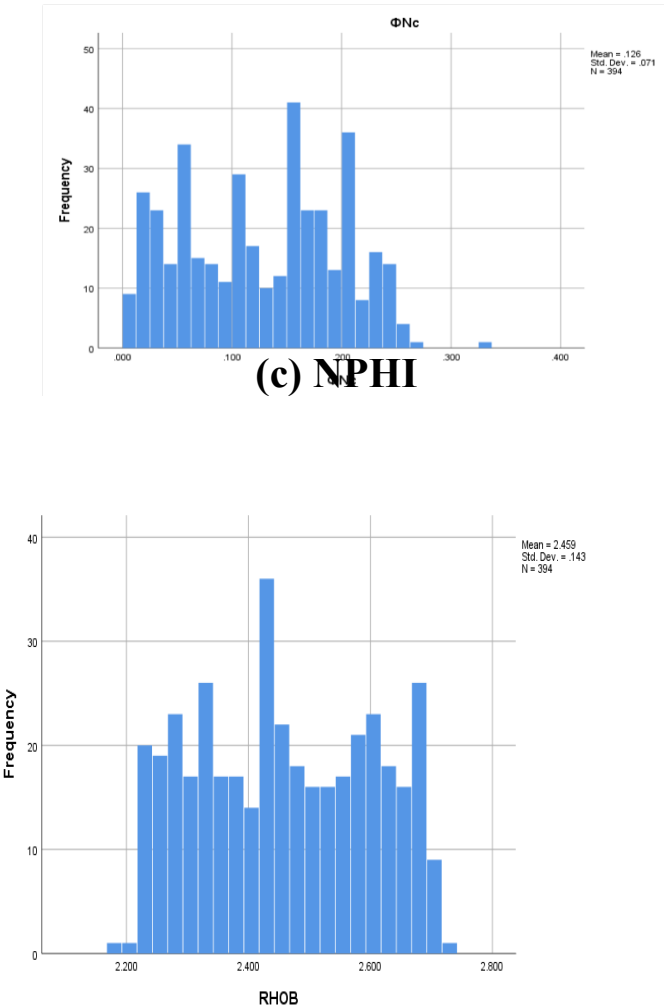

(e) Bulk density

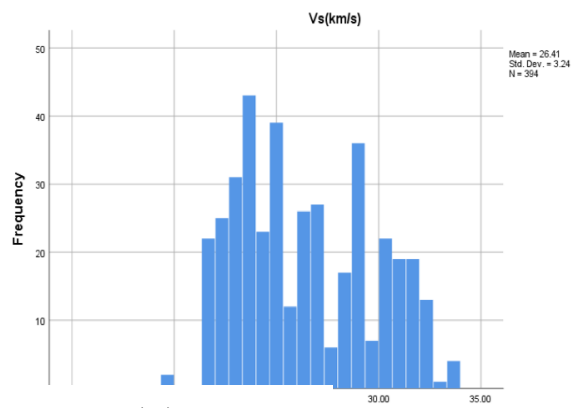

(b) Vs

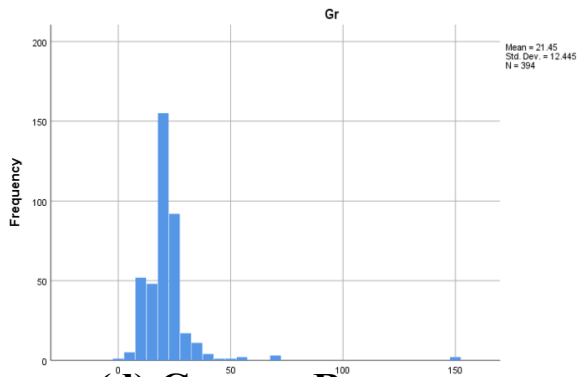

(d) Gamma Ray

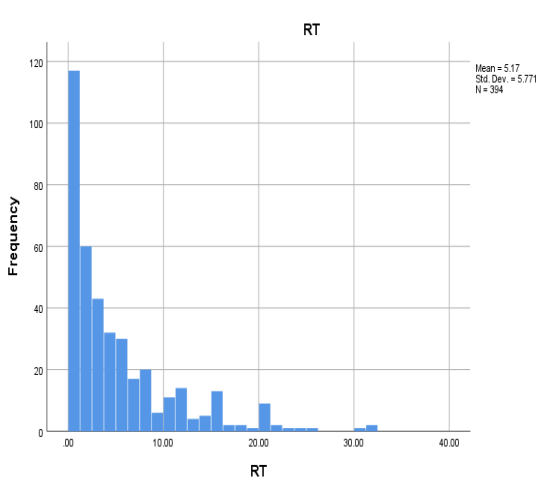

(f) Deep resistivity

Fig. 1: Histograms and statistical evaluations of the set data used (a) compressional wave Velocity( b) shear wave velocity (c) Neutron Porosity (d) Gamma-ray (e) Bulk density and (f)LLD (Rt) for the 394 samples used in this study 
Table 2: Summary of statistical data used in this study

\begin{tabular}{|c|c|c|c|c|c|c|c|}
\hline \multicolumn{8}{|c|}{ Statistics } \\
\hline & & $\begin{array}{c}\mathrm{Vp} \\
(\mathrm{km} / \mathrm{s})\end{array}$ & $\begin{array}{c}\mathrm{Vs}(\mathrm{km} / \\
\mathrm{s})\end{array}$ & $\Phi N c$ & Rt & GR & $\rho b c$. \\
\hline \multirow[t]{2}{*}{$\mathrm{N}$} & Valid & 394 & 394 & 394 & 394 & 394 & 394 \\
\hline & Missing & 0 & 0 & 0 & 0 & 0 & 0 \\
\hline \multicolumn{2}{|l|}{ Mean } & 4.6126 & 2.4545 & .1259 & 5.1692 & 21.45 & 2.45873 \\
\hline \multicolumn{2}{|c|}{ Std. Error of Mean } & .02916 & .01517 & .00359 & .29073 & .627 & .007195 \\
\hline \multicolumn{2}{|c|}{ Median } & $4.5188^{a}$ & $2.4065^{a}$ & $.1305^{\mathrm{a}}$ & $2.8636^{a}$ & $20.68^{a}$ & $2.44893^{a}$ \\
\hline \multicolumn{2}{|l|}{ Mode } & 5.08 & 2.70 & .15 & .60 & 21 & $2.450^{\mathrm{c}}$ \\
\hline \multicolumn{2}{|c|}{ Std. Deviation } & .57883 & .30112 & .07128 & 5.77085 & 12.445 & .142819 \\
\hline \multicolumn{2}{|c|}{ Variance } & .335 & .091 & .005 & 33.303 & 154.869 & .020 \\
\hline \multicolumn{2}{|l|}{ Skewness } & .295 & .288 & .011 & 1.827 & 6.181 & .036 \\
\hline \multicolumn{2}{|c|}{ Std. Error of Skewness } & .123 & .123 & .123 & .123 & .123 & .123 \\
\hline \multicolumn{2}{|c|}{ Kurtosis } & -1.068 & -1.072 & -1.115 & 3.559 & 58.299 & -1.175 \\
\hline \multicolumn{2}{|c|}{ Std. Error of Kurtosis } & .245 & .245 & .245 & .245 & .245 & .245 \\
\hline \multicolumn{2}{|c|}{ Range } & 2.47 & 1.29 & .32 & 31.65 & 150 & .540 \\
\hline \multicolumn{2}{|l|}{ Minimum } & 3.39 & 1.81 & .01 & .35 & 0 & 2.180 \\
\hline \multicolumn{2}{|l|}{ Maximum } & 5.86 & 3.10 & .33 & 32.00 & 150 & 2.720 \\
\hline \multicolumn{2}{|l|}{ Sum } & 1817.38 & 967.07 & 49.59 & 2036.66 & 8450 & 968.740 \\
\hline \multirow[t]{3}{*}{ Percentiles } & 25 & $4.1092^{b}$ & $2.1926^{b}$ & $.0608^{\mathrm{b}}$ & $1.0636^{b}$ & $16.25^{b}$ & $2.33700^{b}$ \\
\hline & 50 & 4.5188 & 2.4065 & .1305 & 2.8636 & 20.68 & 2.44893 \\
\hline & 75 & 5.0980 & 2.7074 & .1830 & 7.1077 & 24.32 & 2.58467 \\
\hline \multicolumn{8}{|c|}{ a. Calculated from grouped data. } \\
\hline \multicolumn{8}{|c|}{ b. Percentiles are calculated from grouped data. } \\
\hline \multicolumn{8}{|c|}{ c. Multiple modes exist. The smallest value is shown } \\
\hline
\end{tabular}

\section{SELECTION OF INDEPENDENT VARIABLES}

Because of the complexity of the relationship between (Vs) values and all properties of rock and fluid, only important and measurable parameters of rock and fluid properties (that could be obtained through well logging data) were selected as main input parameters of the model. Therefore, the selected parameters should have a significant effect on Vs. In order to find out factors which have the most effect on (Vs), besides, to compare the relationship between shear wave velocity and other parameters and petrophysical logs (Vp, NPHI, RHOB, GR, LLD) showed that there is a close relationship between the velocity of compressional and shear waves, especially in carbonate rocks. Figures ( $2 \& 3$ ) show a good relationship between $\mathrm{Vp}$ and Vs in well No.2 for the measured samples. 


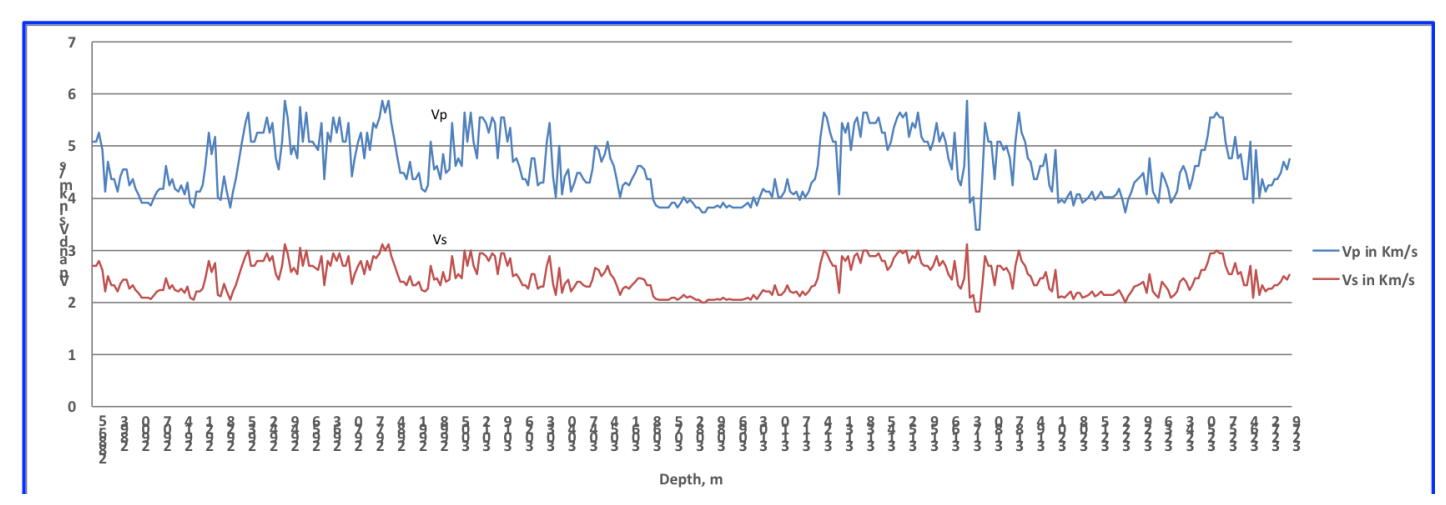

Fig. 2: A good relation between Vp and Vs in well No.2 for the measured samples

To increase the accuracy of the prediction of Vs using regression, other parameters such as neutron porosity (NPHI), density (RHOB), deep resistivity log (LLD) and gamma (GR) were considered for entering to the equation provided in the multiple regressions. Figures $(2$, $3,4,5$ and 6) show the effect of compressional wave velocity, neutron porosity, gamma-ray, density and deep resistivity on shear wave velocity.

\section{CHARACTERISTICS OF INTEREST RESERVOIR AND FIELD}

This work is done in one reservoir of Amara oil field in Mishrif Formation in southeast Iraq, where, shear wave velocity available. Dipole Sonic Imagers (DSI) run in wells 2 for measuring the shear wave velocity. By use of below methods shear wave velocity predicted by available data from mentioned wells.

\section{MODEL DEVELOPMENT}

The main lithology of the interested reservoir is carbonate rocks (Limestone), therefore, the ability of available equation to predict the shear wave velocity in carbonate rocks check in interest reservoir. The presented model from simple regression used the equation below to obtain values of $\mathrm{a} 0$ and $\mathrm{a} 1$. So that, obtain the liner model for calculating the shear wave velocity (equation1).

$V_{s}=a V_{p}+b$

In order to obtain an equation with a better correlation coefficient, we used a statistical method to approach a statistical correlation that calculates shear wave velocity. At first, we used only $\mathrm{Vp}$ from the sonic log as an input. In this way the best equation is as follow:

$V_{s}=0.52 V_{p}+0.0562$ 


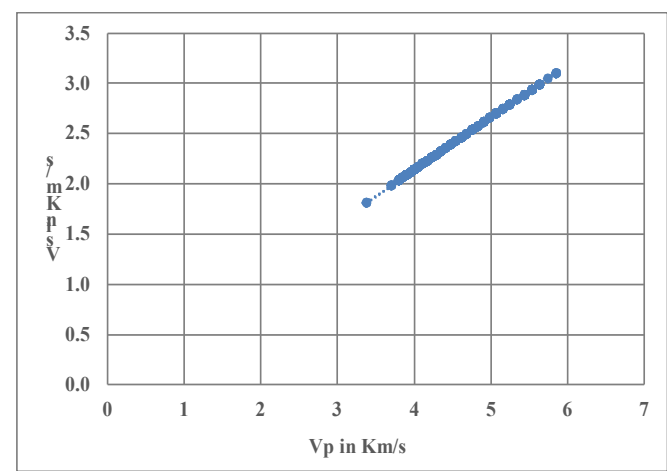

Fig. 3: Shear wave velocity versus compressional velocity for the complete data set used in this study

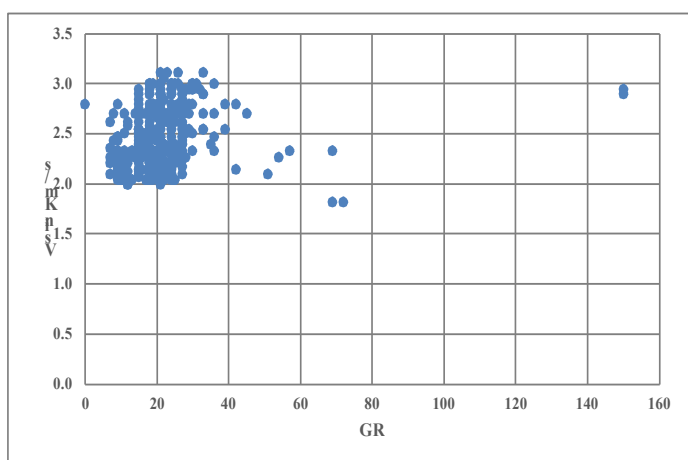

Fig.5: Effect of GR on Vs

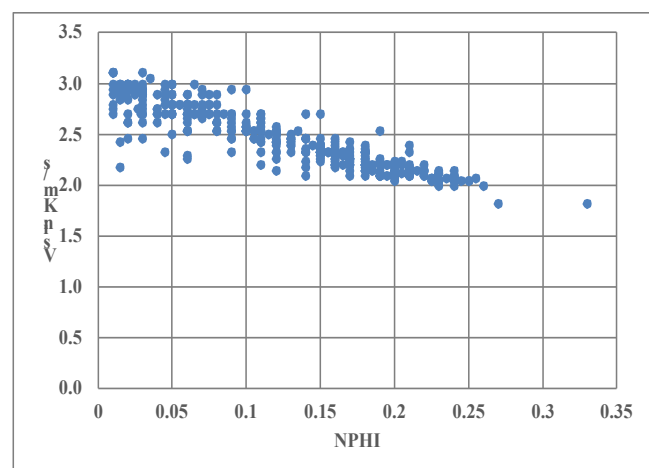

Fig. 4: Effect of NPHI on Vs

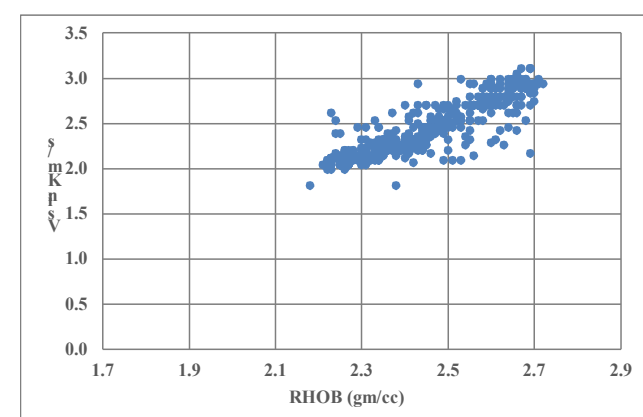

Fig.6: Effect of density on Vs

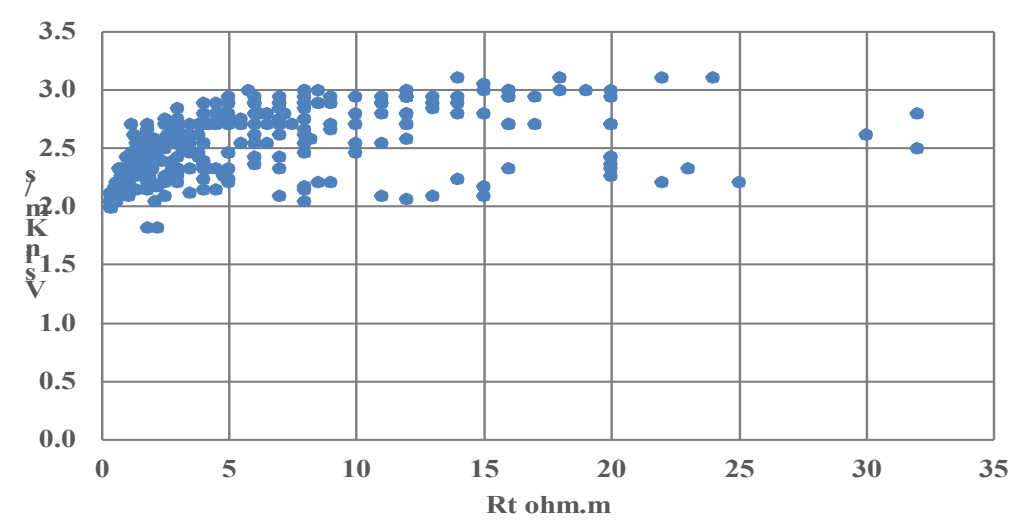

Fig. 7: Effect of LLD on Vs

From Equation (2) shear wave velocity predicted and compared with the real values of shear wave velocity as shown in Figure (8). This equation has one input parameter and the correlation coefficient for this equation is approximately 1 


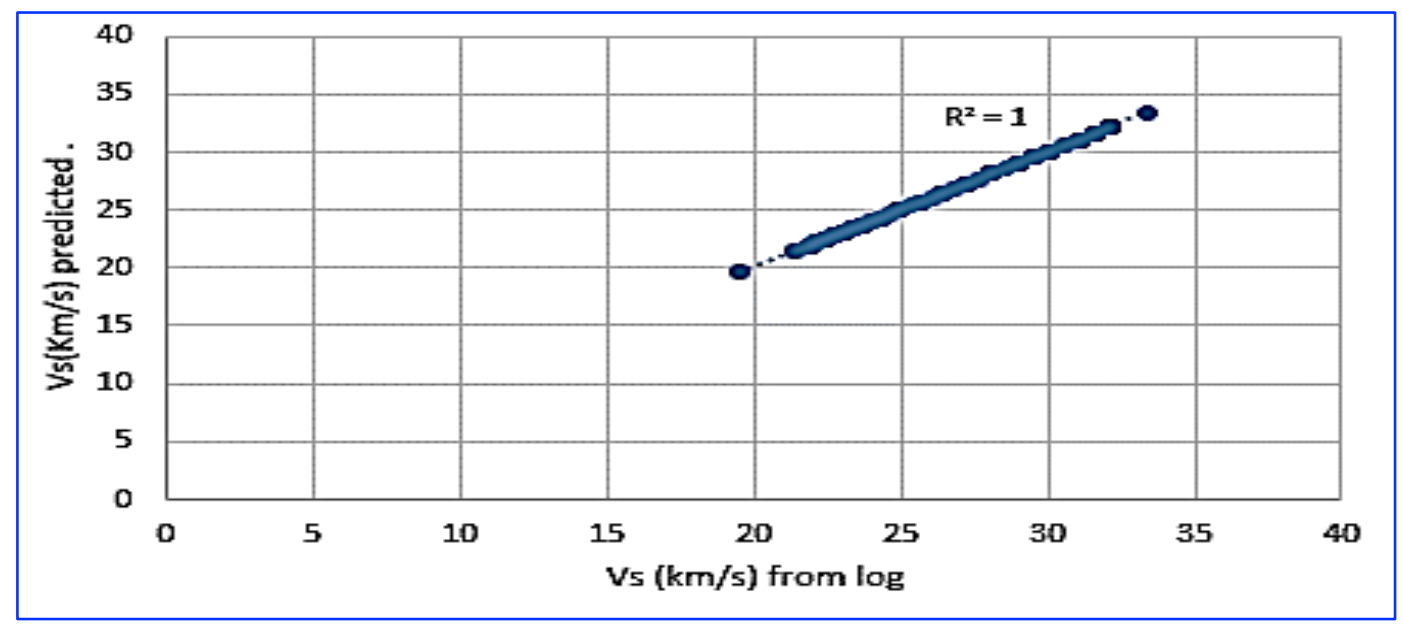

Fig. 8: The relation between the measured shear wave velocity and the predicted shear wave velocity in well 2 using equation (2)

\section{MULTIPLE REGRESSION METHOD}

Regression is a statistical method to estimate a mathematical correlation for determining the unknown variable based on known variable or variables (Pallant, 2013). In this work, shear wave velocity predicted from well logs data, such as NPHI (neutron porosity), RHOB (bulk density), Gamma Ray, deep resistivity and compressional wave velocity by use of multiple regression method in SPSS software. So, first investigate the relation between shear wave velocity and input parameters (NPHI, RHOB, GR, LLD and Vp).

Then, find the coefficients equation (a,b,c, d,e and $f$ ) in the following equation:

$$
\mathrm{Vs}=\mathrm{a}+\mathrm{b} * \mathrm{Vp}+\mathrm{c} * \mathrm{NPHI}+\mathrm{d} * \text { RHOB }+\mathrm{e} * \mathrm{GR}+\mathrm{f} * \mathrm{LLD}
$$

Where, NPHI is neutron porosity expressed as a fraction, RHOB is bulk density in $\mathrm{gm} / \mathrm{cc}, \mathrm{Vp}$ is compressional wave velocity in $\mathrm{km} / \mathrm{s}$ and $\mathrm{Vs}$ is shear wave velocity in $\mathrm{km} / \mathrm{s}$ GR in API and LLD in Ohm.m. It should be noted that, in multiple regression models, using the available data in all wells as input parameters, so that, final model useable in all wells.

The strength of the input variables to predict Vs is given by their degree of contribution to the Vs, which is determined by the multivariate regression analysis. Contribution factors are $(0.058,0.519,-.007,0.001,-5.859 \mathrm{E}-06$, and $-2.641 \mathrm{E}-05$ respectively). It can be seen that the most important variables to this regression are the Vp, NPHI, and RHOB that play significant roles in the model. The weakest variables are the GR and LLD, which means that they must be taken out of the model. The new model was fitted again and the following equation was obtained:

$V s=a 0+b * V p+c * N P H I+d * R H O B$ 
Eq. 4 became as:

$V_{s}=0.058+0.519 V_{p}-0.006 \mathrm{NPHI}+0.001 \mathrm{RHOB}$

The suggested new equation is as follows:

$V_{s}=a+b * V_{p}+c * N P H I+d *(N P H I+e)^{2}+f * \rho b c+\mathrm{g} *(\rho \mathrm{bc}+\mathrm{h})^{2}$

And the eq. 6 using the SPSS software can be written as:

$V s=0.072+0.520 \mathrm{Vp}-0.170 \mathrm{NPHI}-0.106(N P H I-0.902)^{2}+0.05 \rho b c 0.012(\rho b c 0.410)^{2}$

Where Vs and $\mathrm{Vp}$ in $(\mathrm{km} / \mathrm{s})$.

\section{RESULTS AND DISCUSSION}

The estimated Vs using the equation (7) provides a good match with measured Vs as shown in Figure (9) with $\mathrm{R}^{2}$ of about 0.9998 . While Figure (10) presents the computed Vs using equation (7) and log shear wave velocity versus depth for well 2. Multiple regressions presented a robust correlation to predict shear wave velocity from well log data. The multiple linear regressions of the presented variables show a strong correlation among Vs values predicted from well logging data. In these models, shear wave velocity is a function of a few parameters such as compressional wave velocity, porosity and density. Multiple regressions are an extension of the regression analysis that incorporates additional independent variable in the predictive equation. All two methods, empirical and multiple regressions were applied to $\log$ data to predict shear wave velocity for the carbonate reservoir. The results show that the statistical method performs better than empirical models, which can be used only to obtain an order of magnitude for shear wave velocity.

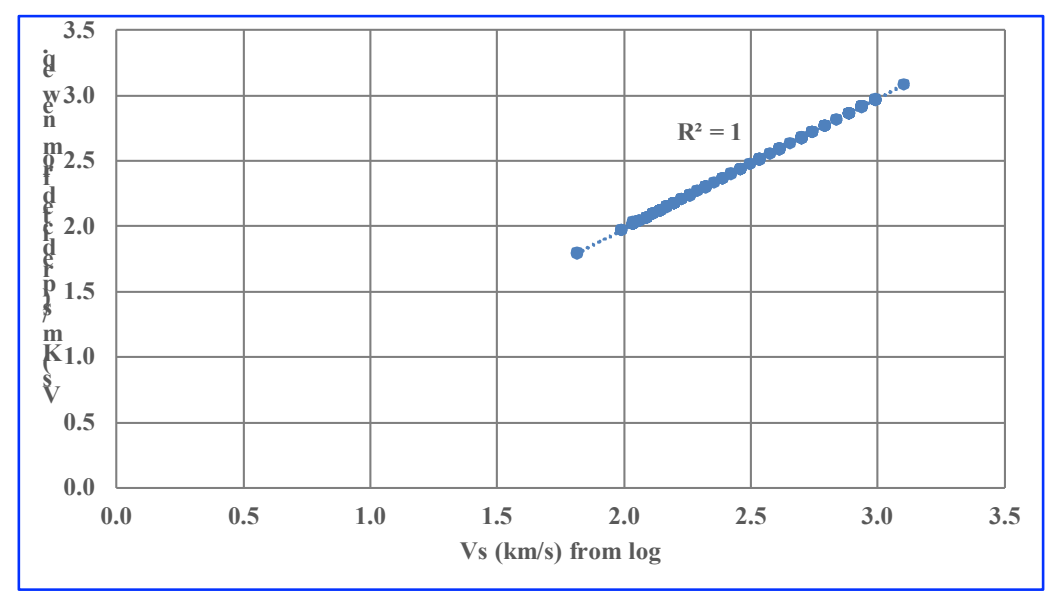

Fig. 9: Plots of predicted Vs using Multivariate regression equation (Equation 7) versus measured Vs from log 


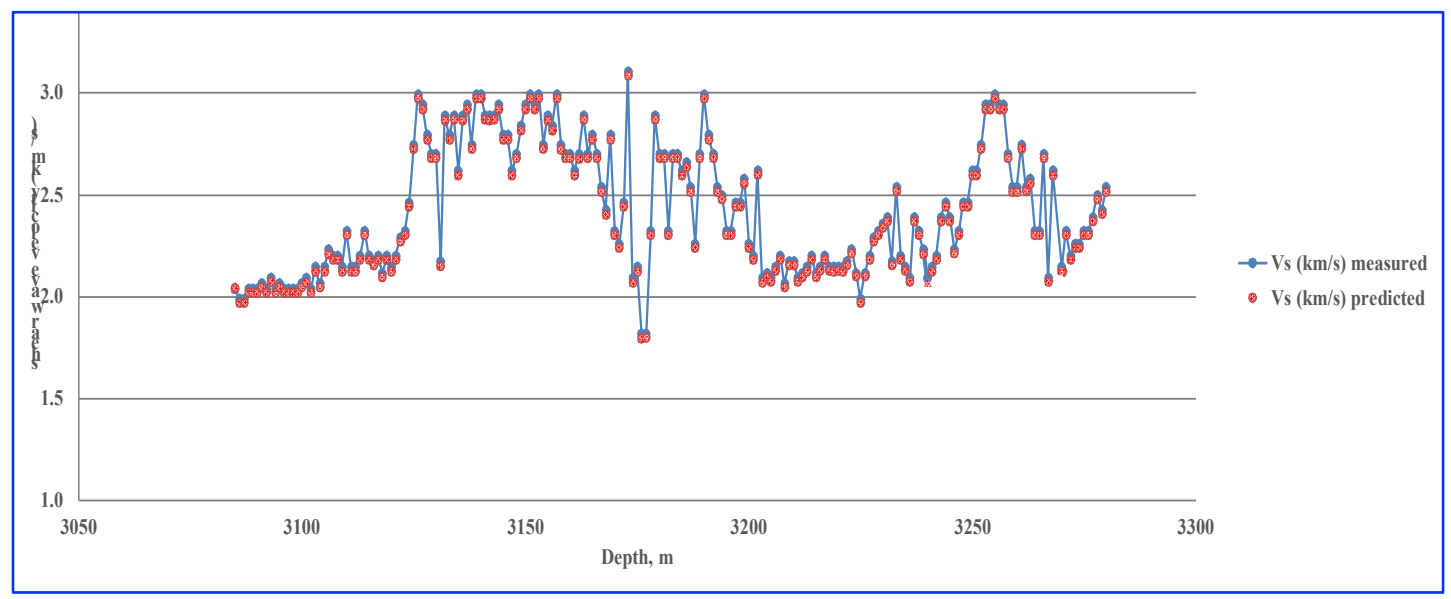

Fig. 10: Measured and predicted Vs using Multivariate regression equation (Equation 16)

Checking the relation between output parameter (Vs) and input parameters (RHOB, NPHI and Vp), by use of the analysis module in SPSS software performed multiple regression between output and input parameters (equation 7) in well Am-2 then, we use the empirical correlation proposed in eq.7 to estimate shear wave velocity predicted in well Am-3. Figure (11) shows the relation between real and predicted shear wave velocity values in well Am-3.

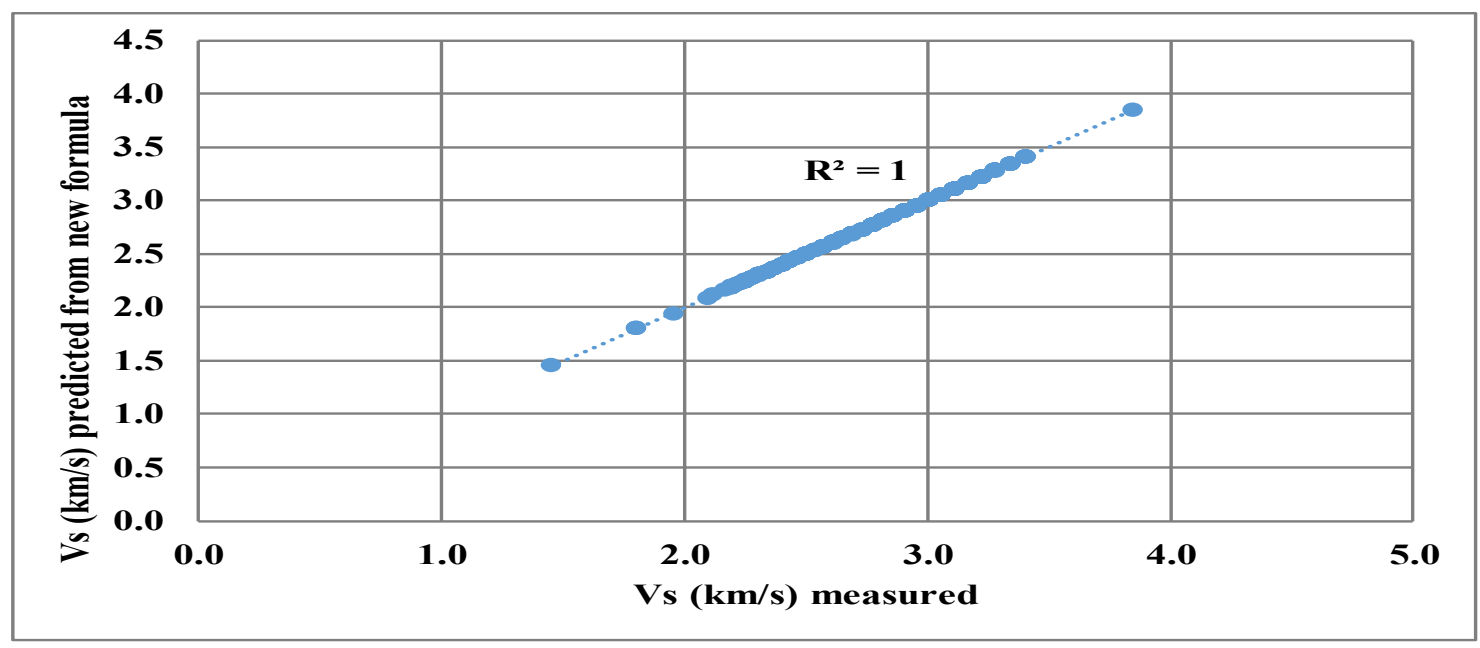

Fig. 11: Plots of predicted Vs using Multivariate regression equation (Equaion 7) versus measured Vs from log for well Am-3

\section{CONCLUSIONS}

This study has investigated the prediction of the shear wave velocity in one reservoir of one of the South-East Iraqi oil fields based on available well log data from interest field wells. It is validated that, well logging data are useable data to predict the shear wave velocity, due to continuous and actual values of these parameters. In this study, we used sonic log as input 
information of regression. It is observed that the most important variable to this regression, which considers as intrinsic properties of rock such as the P-wave velocity (Vp), NPHI, and RHOB that play significant roles in the statistical model. It has been demonstrated that the Swave velocity can be estimated from P-wave velocity, porosity and density if the dipole sonic $\log$ is not available. The introduced equation predicts shear wave velocity for carbonate reservoir with $\mathrm{R}^{2}$ of close to 1 .

\section{REFERENCES}

Ameen, M.S., Smart, B.G., Somerville, J.M., Hammilton, S., and Naji, N.A., 2009. Predicting rock mechanical properties of carbonates from wireline logs (A case study: Arab-D reservoir, Ghawar field, Saudi Arabia). Marine and Petroleum Geology, 26(4): 430-444.

Al-Katan, W.M., 2015. Prediction of Shear Wave velocity for carbonate rocks. Iraqi Journal of Chemical and Petroleum Engineering, 6(4):45- 49.

Al-Kattan, W.M., 2008. A Comprehensive Approach to the Interlock between the Carbonate Rock Mechanical Properties, and Cementation Factor. Thesis submitted to the College of Engineering, Petroleum Dept., University of Baghdad.

Bagheripour, P., Gholami, A., Asoodeh, M., and Asadi, M.V., 2015. Support vector regression-based determination of shear velocity. Journal of Petrolum Sci. Eng. 125:95-99.

Brocher, T.M., 2005. Empirical relations between elastic wave speeds and density in the Earth's crust. Bulletin of the Seismological Society of America, 95(6):2081-2092.

Carroll, R.D., 1969. The determination of acoustic parameters of volcanic rocks from compressional velocity measurements. Int. J. Rock Mech. Min. Sci., 6: 557- 579.

Castagna, J. P., Batzle, M. L., and Eastwood, R.L., 1985. Relationship between compressional and shear wave velocities in silicate rocks. Geophysics, 50: 571-581.

Castagna, J. P., and Batzle, M. L., and Kan, T. K., 1993. Rock physics - The link between rock properties and AVO response. In: Offset-dependent reflectivity-theory and practice of AVO analysis: Castagna, J.P. and Backus, M. (Eds.). Society of ExplorationGeophysicists, 135-171.

Dehghan, S., Sattari, G., Chehreh, C. and Aliabadi, M., 2010. Prediction of uniaxial compressive strength and modulus of elasticity for Travertine samples using regression and artificial neural networks. Mining Science and Technology, 20(1): 41-46.

Economides, M.J., Nolte, K.G., 2000. Reservoir Stimulation, John Wiley \& Sons wet Sussex, England, 192200.

Eskandari, H., Rezaee, M.R., and Mohammadina, M., 2004. Application of multiple regression and artificial neural network techniques to predict shear wave velocity from wireline log data for carbonate reservoir, South-West Iran. CSEG Recorder, 42: 40- 48.

Freund, D., 1992. Ultrasonic compressional and shear velocities in dry clastic rocks as a function of porosity, clay content, and confining pressure. Geophys. J. Int.,108 (1): 125-135.

Greenberg, M., and Castagna, J., 1992. Shear-wave velocity estimation in porous rocks: Theoretical formulation, preliminary verfication and applications. Geophysical Prospecting, 40(2):195-209.

Han, D., Nur, A., and Morgan, D., 1986. Effects of porosity and clay content on wave velocities in sandstones. Geophysics, 51:2093-2107.

Kumar, J., 1976. The Effect of Poisson's Ratio on Rock Properties. In Proceedings of SPE Annual Fall Technical Conference and Exhibition, New Orleans, Louisiana, 36 Oct 1976. SPE 6094.

Maleki, S., Moradzadeh, A., Riabi, R.G., Gholami, R., and Sadeghzadeh, F., 2014. Prediction of shear wave velocity using empirical correlations and artificial intelligence methods. NRIAG J. Astron. Geophys., 3: 7081.

Nourafkan, A., and Ilkhchi, A., 2015. Shear wave velocity estimation from conventional well log data by using a hybrid ant colony - fuzzy inference system: a case study from Cheshmeh - Khosh oil field. J. Pet. Sci. Eng., 127: 459-468.

Omnes, G., 1978. Exploring with SH-waves. J. Can. Soc. Explor. Geophys. 14: 40-49. 
Philip, N.S., 2001. Studies in Artificial Neural Network Modeling. Thesis submitted to the Cochin University of Science and technology, Kochi-22, India.

Pallant, J., 2013. SPSS survival manual: A step by step guide to data analysis using IBM SPSS,4th ed., Crow's Nest, NSW: Allen \& Unwin.

Pickett, G.R., 1963. Acoustic character logs and Their Application in Formation Evaluation. J. Pet. Tech. June, 15(6).

Rajabi, M., Bohloli, B., and Ahangar, E., 2010. Intelligent approach for prediction of compressional, shear and stoneley wave velocities from conventional well log data: a case study from the Sarvak carbonate reservoir in the Abadan plain (Southern Iran). Comput. Geosci., 36: 647-664.

Rezaee, M.R., Ilkhchi, A.K., and Barabadi, A., 2007. Prediction of Shear Wave Velocity from Petrophysical Data Utilizing Intelligent Systems: An Example from a Sandstone Reservoir of Carnarvon Basin. Australian Journal of Petroleum Science and Engineering, 55: 201-212.

Tabari, K., Tabari, O., and Tabari, M., 2011. A fast method for estimating shear wave velocity by using neural network. Aust. J. Basic Appl. Sci., 5:1429-1434.

Tariq, Z., Elkatatny, S., Mahmoud, M., and Abdulraheem, A., 2016. A new artificial intelligence based empirical correlation to predict sonic travel time. International Petroleum Technology Conference. International Petroleum Technology Conference.

Wang, Z., 2000. Velocity relationships in granular rocks, in Wang, Z. and Nur, A., Eds., Seismic and acoustic velocities in reservoir rocks, vol. 3: Recent development, published by Society of Exploration Geophysicists.

Wang, Z., 2000. The Gassmann equation revisited: Comparing laboratory data with Gassmann's predictions. Geophysics, 56: 8- 23.

Widarsono, B., Wong, P.M., and Saptono, F., 2001. Estimation of Rock Dynamic Elastic Property Profiles through a Combination of Soft Computing, Acoustic Velocity Modeling, and Laboratory Dynamic Test on Core Samples.

Zoveidavianpoor, M., Samsuri, A., and Shadizadeh, S., 2013. Prediction of compressional wave velocity by an artificial neural network using some conventional well logs in a carbonate reservoir. Journal of Geophysics and Engineering. 